Pak. j. sci. ind. res. Ser. A: phys. sci. 2017 60(3) 122-127

\title{
Schiff Bases Derived from 1-Aminoanthraquinone: A New Class of Analgesic Compounds
}

\author{
Ghulam Fareed $^{\mathrm{a} *}$, Ghazala Hafeez Rizwani ${ }^{\mathrm{b}}$, Maryam Ahmed ${ }^{\mathrm{b}}$, \\ Muhammad Ali Versianic and Nazia Fareed ${ }^{\mathrm{c}}$

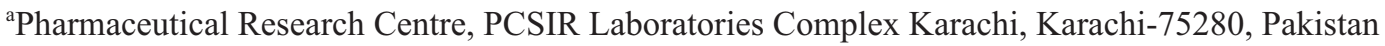 \\ ${ }^{b}$ Department of Pharmacognosy, Faculty of Pharmacy, University of Karachi, Karachi-75270, Pakistan \\ 'Department of Chemistry, Federal Urdu University of Arts, Science and Technology, Karachi, Pakistan
}

(received June 2, 2017; revised June 20, 2017; accepted June 21, 2017)

\begin{abstract}
A series of Schiff bases 1-17 were synthesised by way of a facile condensation between 1-aminoanthraquinone with a variety of carbonyl compounds in the presence of a catalytic amount of dodecatungstosilicic acid $/ \mathrm{P}_{2} \mathrm{O}_{5}$ under solvent free conditions at room temperature. These were charachterised by ${ }^{1} \mathrm{H}$ - and ${ }^{13} \mathrm{C}-\mathrm{NMR}$, LCMS, FTIR and elemental analyses. All the compounds were screened for their analgesic activity using hot plate thermal stimuli method at dose of 10 and $30 \mathrm{mg} / \mathrm{kg}$. Diclofenac sodium was used as a reference drug. All the compounds at dose of 10 and $30 \mathrm{mg} / \mathrm{kg}$ body weight showed the significant $(\mathrm{p}<0.05)$ increase in latency time as compared to control (normal saline). Compound $\mathbf{5}$ showed excellent activity after $120 \mathrm{~min}$ of drug administration $(10 \mathrm{mg} / \mathrm{kg})$ of body weight. Compound $\mathbf{1 0}$ was found to be potent $(10.48 \pm 1.19 \mathrm{~s}, 11.27 \pm 1.2 \mathrm{~s}$ and $10.24 \pm 1.9 \mathrm{~s})$ at dose of $30 \mathrm{mg} / \mathrm{kg}$ at 30,60 and $120 \mathrm{~min}$, respectively when compared to the standard drug. Compound $6(10.13 \pm 0.4 \mathrm{~s})$ was also found to be an excellent analgesic compound at a dose of $30 \mathrm{mg} / \mathrm{kg}$ at $120 \mathrm{~min}$. However, the studies on analgesic activity revealed that some of the target compounds may be strong candidates as an analgesic drug.
\end{abstract}

Keywords: schiff bases, 1-aminoanthraquinone, analgesic compound

\section{Introduction}

Pain is a typical sensory experience that may be described as the unpleasant awareness of a noxious stimulus or bodily harm. It is initiated by stimulation of nociceptors in the peripheral or central nervous system, or by damage to or malfunction of the peripheral or CNS. The term analgesic means a drug that selectively relieves pain by acting in the CNS or peripheral pain mechanism without significantly altering consciousness (Bennett and Villa, 2000). Non-steroidal anti-inflammatory drugs (NSAIDs) are common medication for the treatment of pain, inflammation and fever. However, the significant side effects have been shown with a long term usage of NSAIDs including serious gastrointestinal lesion, kidney injury and cardiovascular risk. During the last century many analgesics drugs have been reported to possess undesirable side effects and hence, injurious to human health. This necessitated the need to look for new effective and safe analgesic drugs. Moreover, the Schiff bases constituted of heterocycles have attracted attention due to their broad spectrum biological activities including antibacterial (Faizul et al., 2007; More et al., 2001; El-Masry et al., 2000; Baseer et al., 2000; Pandeya *Author for correspondence; E-mail: fareedchm@yahoo.com et al., 1999), antifungal (Singh and Dash, 1998), antitumor (Hodnett and Dunn, 1970), anticancer (Desai et al., 2001), herbicidal (Samadhiya and Halve, 2001), antiproliferative (Nawrocka et al., 2006), anti-convulsant (Verma et al., 2004; Kaplan and Rizon, 1980), antioxidant (Fareed et al., 2013a; 2013b; Rada and Leto, 2008; Almasirad et al., 2006), anti-malarial (Tsafack et al., 1996; Clarke and Eaton, 1990) and analgesic drugs.

In view of the wide applications of Schiff bases in the drug design, a facile one pot synthesis (Fareed et al., 2013c) of Schiff bases 1-17 has been in the present study reported. Direct condensation of 1-aminoanthraquinone with a variety of carbonyl compounds was done in the presence of catalytic amount of dodecatungstosilicic $\mathrm{acid} / \mathrm{P}_{2} \mathrm{O}_{5}$ (scheme 1). All the synthesized compounds were subjected to pharmacological screening and showed varying degrees of analgesic activity. However, the studies on analgesic activity revealed that some of the target compounds may be strong candidates as an analgesic drug.

\section{Materials and Methods}

Apparatus. The melting points were recorded in glass capillary using Gallenkamp MF-370 melting point 
apparatus and are uncorrected. ${ }^{1} \mathrm{H}-\mathrm{NMR}(300 \mathrm{MHz})$ and ${ }^{13} \mathrm{C}-\mathrm{NMR}(75 \mathrm{MHz})$ spectra were recorded on Bruker AV-300 NMR Spectrometer in DMSO- $\mathrm{d}_{6}$ with trimethyl silane (TMS) as an internal standard. IR spectra were recorded on Nicolet Avatar 300 DTGS. Mass spectra were recorded on a Finnigan LCQ Advantage Max. Elemental analyses were performed on a Carlo Erba Strumentazion-Mod-1106 instrument. The purity of compounds was determined by using thin layer chromatography (TLC) on pre-coated silica gel glass plates (Kieselgel 60, 254, E. Merck, Germany), visualized under UV at 254 and $365 \mathrm{~nm}$ or in iodine vapours.

General method for the synthesis of Schiff bases 1-17. A mixture of 1-aminoanthraquinone (1 mmol), carbonyl compounds $(1 \mathrm{mmol})$ and $\mathrm{H}_{84} \mathrm{O}_{40} \mathrm{SiW}_{12} / \mathrm{P}_{2} \mathrm{O}_{5}$ ( $0.2 \mathrm{~g}, 1 \mathrm{~mol} \%$ of 1 -aminoanthraquinone $/ \mathrm{P}_{2} \mathrm{O}_{5}$ ) as a<smiles>Nc1cccc2c1C(=O)c1ccccc1C2=O</smiles>

$\mathrm{R}$

1<smiles>CC(C)(C)c1ccc([N+](=O)[O-])cc1</smiles>

2<smiles>Cc1cccc([N+](=O)[O-])c1</smiles>

3<smiles>CC1=CC=C(O)CC1O</smiles>

4<smiles>Cc1ccc(N(C)C)cc1</smiles>

5<smiles>CC(Br)=Cc1ccccc1</smiles>

6<smiles>Cc1cc(Br)c(O)c(Br)c1</smiles>

7

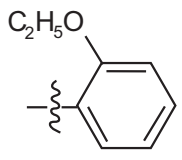

8

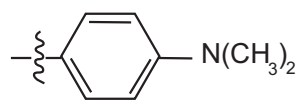

9<smiles>CC(C)c1ccccc1O</smiles>

10<smiles>COc1ccc(C[CH]C(C)C)cc1</smiles>

11

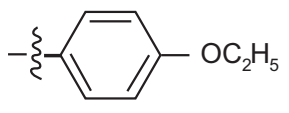

12
13<smiles>[R]C=Nc1cccc2c1C(=O)c1ccccc1C2=O</smiles>

1-17

R<smiles>Cc1cccc(O)c1C</smiles>

14<smiles>CC(C)(C)c1ccco1</smiles>

15<smiles>COc1cc(C(C)(C)C)ccc1C</smiles>

16<smiles>CC(C)(C)c1ccc(O)c(Br)c1</smiles>

17

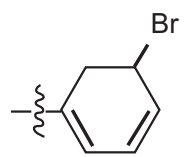

Scheme 1. Structures of synthesized Schiff bases 1-17. 
catalyst were ground under solvent free conditions at room temperature for 1-3 min (scheme 1). Crushed ice was added to afford precipitates of the Schiff bases. In order to remove catalyst, the product was washed several times with ice cooled water. The solid products were obtained in excellent yield (Fareed et al., 2013d).

Analgesic activity. Animals. Wistar rats weighing between 100-170 g were used for the analgesic studies. The animals were of either sex and maintained under $22 \pm$ $1{ }^{\circ} \mathrm{C}$ with a controlled dark and light cycle (12 h: $\left.12 \mathrm{~h}\right)$, with food and water ad libitum. All the experimental animals and protocol had been made according to the guidelines and approval from local ethical committee as per agreement with the Declaration of Helsinki.

Analgesic testing. In the present study analgesia was assessed by thermal nociception through the hot/cold plate device (model no: 35100, UGO Basile, Italy). This apparatus was switched on to heat the surface of the hot plate to a constant temperature of $55 \pm 0.5^{\circ} \mathrm{C}$. The rat of each group was dropped on the hot plate (20 $\mathrm{cm}$ diameter), which was surrounded by a clear acrylic protective casing $(25 \mathrm{~cm}$ height with an open top) so as to obtain its response to electrical heat induced pain stimulus. Rats were divided into 14 groups each comprising of six animals. The sample was given orally with the help of feeding canula in a dose of 10 and 30 $\mathrm{mg} / \mathrm{kg}$ body weight. The experimental animals received diclofenac sodium $(50 \mathrm{mg} / \mathrm{kg})$ as standard drug and $0.9 \%$ saline as control. The initial readings were taken immediately before administration of test drugs followed by intervals of 30,60,120 and $180 \mathrm{~min}$, respectively. The rat paw withdrawal latency, reflected by hind paw licking, flicking, or jumping, was recorded as reaction time (in sec) (Lanthers et al., 1992).

Percent analgesic score was calculated as, $\mathrm{PAS}=\mathrm{T}_{\mathrm{b}}-\mathrm{T}_{\mathrm{a}} / \mathrm{T}_{\mathrm{b}} \times 100$

where:

$\mathrm{T}_{\mathrm{b}}=$ reaction time before drug administration

$\mathrm{T}_{\mathrm{a}}=$ reaction time after drug administration

Statistical analysis. The data are expressed as mean values $\pm \mathrm{SEM}$. The time of latency in the hot plate test and significant differences were obtained by using oneway analysis of variance (ANOVA) and Turkey's as posthoc test, with $\mathrm{p}<0.05$ and $\mathrm{p}<0.01$ as statistically significant. Statistical tests were carried out using SPSS version 20.0 statistical software.

\section{Results and Discussion}

Chemistry. The targeted compounds 1-17 were synthesised according to the previously reported methodology as described in the experimental, and subsequently characterised by LCMS, ${ }^{1} \mathrm{H}$ - and ${ }^{13} \mathrm{C}-\mathrm{NMR}$, IR, and $\mathrm{CHN}$ analyses. Their ${ }^{1} \mathrm{H}-\mathrm{NMR}$ spectra showed the signal of proton of the azomethine moiety $(-\mathrm{N}=\mathrm{CH}-\mathrm{Ar})$ in the range of 7.4-8.9 ppm, while the aromatic protons appeared as a multiplet in the range of 6.74-7.90 ppm. In IR spectra the stretching of $\mathrm{N}=\mathrm{C}$ appeared in the region of 1511-1545 $\mathrm{cm}^{-1}$.

Analgesic activity. In the evaluation of analgesic efficacy of compounds the most common protocol is hot plate method. All the synthesised Schiff bases were tested at doses of 10 and $30 \mathrm{mg} / \mathrm{kg}$ body weight and showed significant $(\mathrm{p}<0.05)$ increase in latency time as compared to the control. A maximum effect was established at 180 min after drug administration. Diclofenac sodium was used as a standard drug and normal saline as control. The results of analgesic activity are presented in Tables 1-2, respectively.

The compound 6 bearing 3,5-dibromo-4-hydroxyphenyl and compound $12 p$-methyl phenyl substituents showed potent activity $(9.30 \pm 1.56 \mathrm{~s}$ and $9.26 \pm 1.18 \mathrm{~s})$, respectively after $30 \mathrm{~min}$ of $10 \mathrm{mg} / \mathrm{kg}$ of drug administration compared to the standard drug. Activity of compound $\mathbf{6}$ and 3,5-dibromo-4-hydroxyphenyl substituent sustained at a level of $9.86 \pm 0.6 \mathrm{~s}$ after $60 \mathrm{~min}$. Compound 5 containing $\alpha$-bromocinnamyl group showed excellent activity after $120 \mathrm{~min}$ of drug administration $(10 \mathrm{mg} / \mathrm{kg})$. Compound 15 containing 3-methoxy-4-hydroxyphenyl group also showed significant activity $(7.2 \pm 0.46 \mathrm{~s})$ after $180 \mathrm{~min}$ of $10 \mathrm{mg} / \mathrm{kg}$. Rest of the compounds showed moderate analgesic activity at $10 \mathrm{mg} / \mathrm{kg}$ of dose administration in comparison to diclofenac sodium as shown in Table 1. Compounds $\mathbf{1}$ having $p$-nitro phenyl substituent and compound 9 bearing 2-hydroxyacetophenyl group showed significant activity at a dose of $30 \mathrm{mg} / \mathrm{kg}$ after $30 \mathrm{~min}(9.7 \pm 1.22 \mathrm{~s}$ and $9.11 \pm 0.67 \mathrm{~s})$, respectively. Compound 8 also showed good analgesic activity after 60 and $120 \mathrm{~min}$ of dose administration of $30 \mathrm{mg} / \mathrm{kg}$. Compound 10 containing $p$-methoxycinnamyl group was found to be potent $(10.48 \pm 1.19 \mathrm{~s}, 11.27 \pm 1.2 \mathrm{~s}$ and $10.24 \pm 1.9 \mathrm{~s})$ at a dose of $30 \mathrm{mg} / \mathrm{kg}$ at time intervals of 30, 60 and $120 \mathrm{~min}$, respectively. Compounds $\mathbf{1}$ and $\mathbf{5}$ showed significant activity after $120 \mathrm{~min}(9.17 \pm 1.3 \mathrm{~s}$ and $9.73 \pm 1.6 \mathrm{~s})$, respectively. Compound $6(10.13 \pm 0.4)$ was also found to be an excellent analgesic compound 
Table 1. Analgesic activity by hot plate method at dose of $10 \mathrm{mg} / \mathrm{kg}$

\begin{tabular}{llllll}
\hline \hline \multirow{2}{*}{ Compounds } & \multicolumn{5}{c}{ Reaction time in sec \pm SEM* } \\
\cline { 2 - 5 } & 0 min & 30 min & 60 min & 120 min & 180 min \\
\hline Control (normal saline) & $7.13 \pm 0.18$ & $6.23 \pm 0.55$ & $5.76 \pm 0.2$ & $4.83 \pm 0.2$ & $4.69 \pm 0.2$ \\
Diclofenac sodium & & & & \\
$(50 \mathrm{mg} / \mathrm{kg})$ & $7.49 \pm 0.32$ & $10.81 \pm 0.15$ & $11.3 \pm 0.2$ & $11.93 \pm 0.2$ & $11 \pm 0.1$ \\
$\mathbf{1}$ & $5.54 \pm 0.27$ & $5.83 \pm 0.46$ & $5.86 \pm 0.52$ & $6.24 \pm 0.56$ & $5.69 \pm 0.36$ \\
$\mathbf{2}$ & $5.67 \pm 0.5$ & $6.79 \pm 0.58$ & $6.44 \pm 0.31$ & $6.77 \pm 0.7$ & $6.1 \pm 0.25$ \\
$\mathbf{3}$ & $5.91 \pm 1.14$ & $6.16 \pm 1.27$ & $6.4 \pm 1.4$ & $6.03 \pm 1.1$ & $6.53 \pm 1.2$ \\
$\mathbf{4}$ & $5.54 \pm 0.3$ & $6.55 \pm 0.29$ & $6.81 \pm 0.4$ & $5.89 \pm 0.58$ & $5.46 \pm 0.8$ \\
$\mathbf{5}$ & $7 \pm 0.68$ & $7.4 \pm 0.2$ & $8.73 \pm 0.9$ & $10.13 \pm 1.7 * *$ & $8.93 \pm 1.88^{* *}$ \\
$\mathbf{6}$ & $7.97 \pm 0.9$ & $9.30 \pm 1.56^{*}$ & $9.86 \pm 0.6 *$ & $8.67 \pm 1.28^{*}$ & $9.57 \pm 0.99^{* *}$ \\
$\mathbf{7}$ & $5.11 \pm 0.04$ & $6.27 \pm 0.17$ & $7.48 \pm 0.98$ & $7.53 \pm 0.7$ & $6.03 \pm 0.68$ \\
$\mathbf{8}$ & $5.29 \pm 0.35$ & $6.08 \pm 0.77$ & $7.83 \pm 2.6$ & $7.17 \pm 0.27$ & $6.61 \pm 0.2$ \\
$\mathbf{9}$ & $7.77 \pm 1.4$ & $8.06 \pm 1.27$ & $7.84 \pm 0.9$ & $7.58 \pm 0.5$ & $8.97 \pm 1.27^{* *}$ \\
$\mathbf{1 0}$ & $7.47 \pm 0.18$ & $8.94 \pm 1.9 * *$ & $8.76 \pm 2.5$ & $8.36 \pm 2.9 *$ & $6.65 \pm 1.8$ \\
$\mathbf{1 1}$ & $5.45 \pm 1.2$ & $4.91 \pm 0.7$ & $5.03 \pm 0.6$ & $5.47 \pm 0.59$ & $6.06 \pm 0.9$ \\
$\mathbf{1 2}$ & $8.16 \pm 1.1$ & $9.26 \pm 1.18^{* *}$ & $8.22 \pm 0.8$ & $6.34 \pm 0.4$ & $6.33 \pm 0.5$ \\
$\mathbf{1 3}$ & $3.9 \pm 0.5$ & $4.2 \pm 0.5$ & $4.8 \pm 0.5$ & $6.3 \pm 0.8$ & $6.4 \pm 1.1$ \\
$\mathbf{1 4}$ & $4.06 \pm 0.2$ & $4.6 \pm 0.2$ & $5.4 \pm 0.08$ & $6.2 \pm 0.1$ & $6.5 \pm 0.38$ \\
$\mathbf{1 5}$ & $4.73 \pm 0.4$ & $5.1 \pm 0.6$ & $6.0 \pm 0.6$ & $6.6 \pm 0.7$ & $7.2 \pm 0.46^{*}$ \\
$\mathbf{1 6}$ & $3.9 \pm 0.6$ & $4.3 \pm 0.58$ & $4.1 \pm 0.2$ & $5.2 \pm 0.5$ & $7.1 \pm 0.5$ \\
$\mathbf{1 7}$ & $3.7 \pm 0.4$ & $3.8 \pm 0.57$ & $4.3 \pm 0.4$ & $5.1 \pm 1.6$ & $6.9 \pm 1.6$ \\
\hline \hline
\end{tabular}

All values are mean \pm SEM, $n=6 ; *$ SEM = standard error of mean; One way analysis of variance (ANOVA) followed by Tukey's as post-hoc test whereas $\mathrm{p}<0.05$ was considered significant. $\mathrm{p}<0.01$ was considered to be more significant; ${ }^{*} \mathrm{p}<0.05$; ${ }^{* *} \mathrm{p}<0.01$ as compared with control group.

Table 2. Analgesic activities by hot plate method at dose of $30 \mathrm{mg} / \mathrm{kg}$

\begin{tabular}{llllll}
\hline \hline Compounds & \multicolumn{5}{c}{ Reaction time in sec \pm SEM* } \\
\cline { 2 - 6 } & 0 min & 30 min & 60 min & 120 min & 180 min \\
\hline Control & $7.13 \pm 0.18$ & $6.23 \pm 0.55$ & $5.76 \pm 0.2$ & $4.83 \pm 0.2$ \\
Diclofenac sodium & & & & \\
$(50 \mathrm{mg} / \mathrm{kg})$ & $7.49 \pm 0.32$ & $10.81 \pm 0.15$ & $11.3 \pm 0.2$ & $11.93 \pm 0.2$ & $11 \pm 0.1$ \\
$\mathbf{1}$ & $6.89 \pm 0.44$ & $9.7 \pm 1.22^{* *}$ & $7.9 \pm 0.5$ & $9.17 \pm 1.3^{* *}$ & $8.63 \pm 1.4^{*}$ \\
$\mathbf{2}$ & $4.71 \pm 0.41$ & $5.15 \pm 0.19$ & $7.21 \pm 1.2$ & $7.63 \pm 0.6$ & $4.92 \pm 0.9$ \\
$\mathbf{3}$ & $6.40 \pm 1.37$ & $7.04 \pm 1.03$ & $6.85 \pm 1.6$ & $7.51 \pm 2.5$ & $5.54 \pm 1.8$ \\
$\mathbf{4}$ & $5.36 \pm 1.03$ & $5.07 \pm 0.4$ & $6.65 \pm 0.7$ & $5.74 \pm 0.4$ & $5.22 \pm 1.3$ \\
$\mathbf{5}$ & $6.56 \pm 0.45$ & $6.96 \pm 0.4$ & $7.09 \pm 0.5$ & $9.73 \pm 1.6^{* *}$ & $9.1 \pm 1.8^{* *}$ \\
$\mathbf{6}$ & $6.97 \pm 0.14$ & $8.4 \pm 0.817^{*}$ & $8.5 \pm 0.7$ & $10.13 \pm 0.4^{* *}$ & $8.8 \pm 1.6^{*}$ \\
$\mathbf{7}$ & $5.83 \pm 0.32$ & $7.6 \pm 1.12$ & $8.33 \pm 1.4$ & $8.06 \pm 0.7^{*}$ & $8.03 \pm 1^{*}$ \\
$\mathbf{8}$ & $5.33 \pm 0.33$ & $6.98 \pm 0.46$ & $9.8 \pm 1.6^{* *}$ & $8.52 \pm 0.2^{*}$ & $7.27 \pm 0.2$ \\
$\mathbf{9}$ & $7.47 \pm 1.21$ & $9.11 \pm 0.67^{* *}$ & $8.94 \pm 0.3^{*}$ & $7.83 \pm 0.6$ & $7.7 \pm 0.7$ \\
$\mathbf{1 0}$ & $7.47 \pm 0.18$ & $10.48 \pm 1.19^{* *}$ & $11.27 \pm 1.2^{* *}$ & $10.24 \pm 1.9^{* *}$ & $7.03 \pm 0.5$ \\
$\mathbf{1 1}$ & $5.42 \pm 0.94$ & $6.16 \pm 0.68$ & $6.09 \pm 0.4$ & $5.46 \pm 0.6$ & $5.83 \pm 0.7$ \\
$\mathbf{1 2}$ & $7.97 \pm 1.10$ & $7.88 \pm 0.65$ & $8.02 \pm 0.7$ & $7.86 \pm 0.8$ & $7.56 \pm 0.6$ \\
$\mathbf{1 3}$ & $3.9 \pm 0.5$ & $4.1 \pm 0.5$ & $4.6 \pm 0.5$ & $4.8 \pm 0.49$ & $5.2 \pm 0.5$ \\
$\mathbf{1 4}$ & $4.06 \pm 0.26$ & $4.4 \pm 0.3$ & $4.9 \pm 0.2$ & $5.3 \pm 0.2$ & $4.6 \pm 0.38$ \\
$\mathbf{1 5}$ & $4.7 \pm 0.48$ & $5 \pm 0.5$ & $5.4 \pm 0.48$ & $5.8 \pm 0.48$ & $6.1 \pm 0.4^{*}$ \\
$\mathbf{1 6}$ & $3.9 \pm 0.6$ & $4.2 \pm 0.6$ & $5.1 \pm 0.9$ & $5.6 \pm 0.9$ & $5.9 \pm 0.9$ \\
$\mathbf{1 7}$ & $3.7 \pm 0.4$ & $4.2 \pm 0.36$ & $4.5 \pm 0.39$ & $5.1 \pm 0.39$ & $5.6 \pm 0.37$ \\
\hline \hline
\end{tabular}

All values are Mean \pm SEM; $n=6, *$ SEM = standard error of mean; One way analysis of variance (ANOVA) followed by Tukey's as post-hoc test whereas $\mathrm{p}<0.05$ was considered significant; $\mathrm{p}<0.01$ was considered to be more significant; ${ }^{*} \mathrm{p}<0.05$; $* * \mathrm{p}<0.01$ as compared with control group. 
at a dose of $30 \mathrm{mg} / \mathrm{kg}$ at $120 \mathrm{~min}$. Compound 15 also showed significant activity $(6.1 \pm 0.4 \mathrm{~s})$ after $180 \mathrm{~min}$ of $30 \mathrm{mg} / \mathrm{kg}$ dose. Rest of the compounds showed moderate to weak analgesic activity at $30 \mathrm{mg} / \mathrm{kg}$ of dose administration in comparison to diclofenac sodium as shown in Table 2. The SAR study suggests that the analgesic activity enhance with electron donating substituents and extension in conjugation at phenyl group. In this study all the compounds did not reveal any undesirable side effects or behavioral changes. No mortality was observed in a period of about 30 days.

\section{Conclusion}

Compounds 5, 6, 10 and 12 exhibit very significant analgesic activity at a dose of $10 \mathrm{mg} / \mathrm{kg}$. Compounds 9 and $\mathbf{1 0}$ showed potent activity at a dose of $30 \mathrm{mg} / \mathrm{kg}$. In view of the results described here, Schiff bases derived from 1-amino-anthraquinone may leads to a good source of analgesic drug.

\section{References}

Almasirad, A., Hosseini, R., Jalalizadeh, H., RahimiMoghaddam, Z., Abeian, N., Janafrooz, M., Abbaspour, M., Ziaee, V., Dalvandi, A., Shafiee, A. 2006. Synthesis and analgesic activity of 2phenoxybenzoic acid and $N$-phenylanthranilic acid hydrazides. Biological and Pharmaceutical Bulletin, 29: 1180-1185.

Baseer, M.A., Jadhav, V.D., Phule, R.M., Archana, Y.V., Vibhute, Y.B. 2000. Synthesis and antimicrobial activity of some new schiff bases. Orient Journal of Chemistry, 16: 553-556.

Bennett, A., Villa, G. 2000. Nimesulide: An NSAID that preferentially inhibits COX-2, and has various unique pharmacological activities. Expert Opinion on Pharmacotherapy, 1: 277-286.

Clarke, C.J., Eaton, J.W. 1990. Hydrophobic iron chelators as new antimalarial drugs. Clinical Research, 38: 300A.

Desai, S.B., Desai, P.B., Desai, K.R. 2001. Synthesis of some schiff bases, thiazolidones, and azetidinones derived from 2,6-diaminobenzo[1,2-d:4,5d']bisthiazole and their anticancer activities. Heterocyclic Communication, 7: 83-90.

El-Masry, A.H., Fahmy, H.H., Abdelwahed, S.H.A. 2000. Synthesis and antimicrobial activity of some new benzimidazole derivatives. Molecules, 5: 14291438.

Faizul, A., Satendra, S., Sukhbir, L.K., Om, P. 2007.
Synthesis of Schiff bases of naphtha[1,2-d] thiazol2-amine and metal complexes of 2-(2' hydroxy) benzylideneamino naphthothiazole as potential antimicrobial agents. Journal of Zhejiang University Science- $B, 8$ : 446-452.

Fareed, G., Afza, N., Versiani, M.A., Fareed, N., Iqbal, L., Lateef, M., Rehman, T. 2013a. Antioxidant activity and structure activity relationship of some new Schiff bases derived from 2-aminobenzophenone. Medicinal Chemistry and Drug Discovery, 4: 27-34.

Fareed, G., Versiani, M.A., Afza, N., Fareed, N., Iqbal, L., Lateef, M. 2013b. Structure activity relationship: antioxidant potential of some novel Schiff bases containing benzophenone moiety. International Journal of Current Pharmaceutical Research, 5: 61-64.

Fareed, G., Versiani, M.A., Afza, N., Fareed, N., Kalhoro, M.A., Yasmeen, S., Anwar, M.I. 2013c. An efficient catalyst for the synthesis of Schiff bases. Journal of the Chemical Society of Pakistan, 35: 426-430.

Fareed, G., Versiani, M.A., Afza, N., Fareed, N., Ali, M.I., Kalhoro, M.A. 2013d. An efficient synthesis and spectroscopic characterization of schiff bases containing 9, 10-anthracenedione moiety. Journal of the Serbian Chemical Society, 78: 477-482.

Hodnett, E.M., Dunn, W.J. 1970. Structure-antitumor activity correlation of some Schiff bases Journal of Medicinal Chemistry, 13: 768-770.

Karrouchi, K., Chemlal, L., Taoufik, J., Cherrah, Y., Radi, S., El Abbes, Faouzi, M., Ansar, M. 2016. Synthesis, antioxidant and analgesic activities of Schiff bases of 4-amino-1,2,4-triazole derivatives containing a pyrazole moiety. Annales Pharmaceutiques Françaises, 74: 431-438.

Kaplan, J.P., Rizon, B.M. 1980. New anticonvulsants: Schiff bases of gamma-aminobutyric acid and gamma-aminobutyramide. Journal of Medicinal Chemistry, 23: 702-704.

Lanhers, M.C., Fleurentin, J., Mortier, F., Vinche, A., Younos, C. 1992. Antiinflammatory and analgesic effects of an aqueous extract of Harpagophytum procumbens. Planta Medica, 58: 117-123.

More, P.G., Bhalvankar, R.B., Pattar, S.C. 2001. Synthesis and biological activities of Schiff bases of aminothiazoles. Journal of Indian Chemical Society, 78: 474-475.

Nawrocka, W.P., Sztuba, B., Drys, A., Wietrzyk, J., Kosendiak, J., Opolski, A. 2006. Reaction of aromatic aldehydes with 2-aminobenzimidazole 
by using catalytic amount of $\mathrm{M}\left(\mathrm{NO}_{3}\right)_{2} \cdot \mathrm{xH}_{2} \mathrm{O}$. Polish Journal of Chemistry, 80: 279-287.

Pandeya, S.N., Sriram, D., Nath, G., DeClercq, E. 1999. Synthesis and antimicrobial activity of schiff and Mannich bases of isatin and its derivatives with pyrimidine. IL Farmaco, 54: 624-628.

Rada, B., Leto, T.L. 2008. Oxidative innate immune defenses by Nox/Duox family NADPH oxidases. Contribution to Microbiology, 15: 164-187.

Salve, P.S., Alegaon, S.G., Sriram, D. 2017. Threecomponent, one-pot synthesis of anthranilamide Schiff bases bearing 4-aminoquinoline moiety as Mycobacterium tuberculosis gyrase inhibitors. Bioorganic \& Medicinal Chemistry Letters, 27: 1859-1866.
Samadhiya, S., Halve, A. 2001. Synthetic utility of Schiff bases as potential herbicidal agents. Orient Journal of Chemistry, 17: 19-122.

Singh, W.M., Dash, B.C. 1988. Synthesis of some new Schiff bases containing thiazole and oxazole nuclei and their fungicidal activity. Pesticides, 22: 33-37.

Tsafack, A., Loyevski, M., Ponks, P., Cabantchik, Z.I. 1996. Journal of Laboratory and Clinical Medicine, 127: 574-582.

Ugo Basile Biological Research Apparatus Hot/Cold Plate Cat. No. 35100 Instruction Manual.

Verma, M., Pandeya, S.N., Singh, K.N., Stables, J.P. 2004. Anticonvulsant activity of Schiff bases of isatin derivatives. Acta Pharmaceutica, 54: 49-56. 